\title{
NOTAS SOBRE A \\ RECUSA SAUSSURIANA À NOÇÃO DE LÍNGUA COMO REPRESENTAÇÃO
} Glória Monteiro de Carvalho*

(iD) https://orcid.org/0000-0003-0595-1764

Maria de Fátima Vilar de Melo**

(iD) https://orcid.org/0000-0002-2187-9945

Como citar este artigo: CARVALHO, G. M. de; MELO, M. de F. V. de. Notas sobre a recusa saussuriana à noção de língua como representação. Todas as Letras - Revista de Lingua e Literatura, São Paulo, v. 22, n. 2, p. 1-14, maio/ago. 2020. DOI 10.5935/ 1980-6914/eLETDO2013423

Submissão: maio de 2020. Aceite: julho de 2020.

Resumo: Este artigo consiste em uma tentativa de discutir a separação radical entre o signo saussuriano e a noção tradicional de signo linguístico como representação. Procuramos abordar a questão do dualismo interno versus externo em relação à língua e duas consequências advindas dessa questão: a noção de identidade - que implica a noção de corpo do falante - e o dualismo acontecimento versus estado de língua. Colocamos, então, em destaque questões e paradoxos que se tornam visiveis nessa abordagem, pretendendo quebrar a naturalidade com que tem sido tratada a recusa de Saussure à concepção representacional de língua.

Palavras-chave: Saussure. Língua. Signo. Representação. Dualismo. 


\section{INTRODUÇÃO}

I

niciamos este artigo destacando que o gesto inaugural de Ferdinand de Saussure, no campo dos estudos da linguagem, pode ser condensado em sua recusa radical à concepção de língua como representação, recusa daquilo que ele concebe como uma abordagem filosófica da linguagem.

A esse respeito, Lahud (1977, p. 32) se refere à "tradição semiológica ideacional que considera o signo como uma entidade dual de natureza essencialmente representativa". Assim, uma coisa - de natureza material: as palavras - representa outra coisa - de natureza mental: as ideias. Por sua vez, esse caráter representativo do signo implica a concepção de língua como nomenclatura, isto é, a preexistência de objetos ou ideias para os quais são fixados palavras ou nomes.

Segundo Milner (2003, p. 30-31, tradução nossa), "assistimos aqui a um deslocamento decisivo: Saussure constrói um modelo de signo que se separa de toda teoria da representação". Tanto as duas faces do signo - nomeados, a partir de um determinado momento, com os termos significante e significado - apontam para esse deslocamento, quanto à concepção de significante como imagem acústica, o que indica uma realidade psicológica "o representante psíquico da materialidade fônica" (MILNER, 2003, p. 30-31, tradução nossa). Trata-se, portanto, de dois fatos mentais, o significante (imagem acústica) e o significado (conceito), porém, radicalmente diferentes um do outro - embora indissociáveis - e constituindo a noção de signo, não menos radicalmente, diferente da noção tradicional/representativa. Milner (2003, p. 30, tradução nossa) deixa clara essa diferença quando confronta, do ponto de vista lógico, representação e associação, sendo o uso desse último termo decisivo na doutrina saussuriana: "O significante não representa o significado: está associado a ele e, ao mesmo tempo, o significado está associado, por sua vez, ao significante”. Assim, a representação consiste em uma relação assimétrica, isto é, A representa B não implica que B representa A. Por sua vez, A se associa a B implica que B se associa a A, havendo, portanto, reciprocidade nesse último caso.

Considerando apenas o que está no Curso de Linguistica Geral (de agora em diante, CLG), Arrivé (2008, p. 39, tradução nossa) afirma que, para Saussure, "a lingua é ao mesmo tempo 'substância deslizante' e 'sistema fechado'. [Essa] hesitação se reproduz em relação a cada uma das noções colocadas em sua teoria, notadamente a noção de signo".

Arrivé (2008) afirma que, todavia, no tocante ao signo, Saussure propõe "uma solução elegante" que é a de tomar os dois lados de uma vez. A esse respeito, a reflexão saussuriana sobre o signo começa com um gesto de exclusão: a exclusão da "coisa", palavra usada pelo mestre genebrino para o que mais tarde seria chamado de referente. Afirma, então, que "o signo linguístico une não uma coisa e um nome, mas um conceito e uma imagem acústica" (SAUSSURE, 1985 [1916], p. 80).

De acordo com Arrivé (2008, p. 39, tradução nossa), “Essa exclusão da 'coisa' Saussure, nas suas notas, fala mais explicitamente ainda dos 'objetos designados' - é a consequência imediata da recusa de conceber a língua como nomenclatura". Ora, conceber a língua como nomenclatura seria então tomá-la como uma lista de termos que corresponderia à mesma quantidade de coisas (SAUSSURE, 1985 [1916], p. 80). 
Não é que Saussure desconhecesse a relação entre as palavras e as coisas, muito pelo contrário, porém ele assinala "a insuficiência dessa concepção tradicional”. Segundo esse autor, essa relação deixa supor que o elo entre um nome e uma coisa "é uma operação muito simples, o que está bem longe da verdade" (SAUSSURE, 1985 [1916], p. 79).

Arrivé (2008, p. 40, tradução nossa) acrescenta que Saussure confere à fala a realização dessa relação entre as palavras e as coisas; mas isso não contraria o seu propósito de excluir o referente da sua definição de signo "e é isso que distingue a análise de Saussure da quase totalidade dos discursos sobre o tema".

Ao substituir os termos conceito e imagem acústica por significado e significante, as duas faces do signo deixam de ter o que ainda lhes restava de substância, porque era o adjetivo (acústica) que continha um caráter substancial. O linguista genebrino insiste, nos cursos e, mais ainda, nos manuscritos, que "não se trata da substância física do som, mas da sua 'impressão psíquica"' (ARRIVÉ, 2008, p. 40, tradução nossa).

Em consonância com a maioria dos comentadores da obra saussuriana, Arrivé (2008, p. 40) destaca que o real estatuto do signo linguístico depende do valor que lhe é dado pelos termos com os quais ele mantém as relações associativas e sintagmáticas. "Entretanto, são as relações associativas que produzem o 'valor' no que ele tem de mais 'específico' e este afeta os dois lados do signo" (ARRIVÉ, 2008, p. 40, tradução nossa). Resulta dessa proposta "que o 'conteúdo' dos signos que são as palavras não é determinado pelo objeto que as circunstâncias podem lhe dar como referente, mas pela rede das diferenças que as opõem às outras palavras da língua" (ARRIVÉ, 2008, p. 40, tradução nossa).

Saussure (1985 [1916]) propõe que, se as palavras fossem encarregadas de representar conceitos dados anteriormente, elas possuiriam, cada uma, correspondentes exatos, em relação ao seu sentido, nas outras linguas. Colocado dessa maneira, o signo saussuriano é afetado por duas propriedades: o arbitrário e a linearidade. O princípio da arbitrariedade do signo é constante e universal, sendo inseparável da língua como o sistema de valor. Saussure (1985 [1916], p. 132) afirma que:

Essas considerações fazem compreender melhor o que foi dito na página 81 sobre o arbitrário do signo. Não só os dois domínios ligados pelo fato linguístico são confusos e amorfos como a escolha que se decide por tal porção acústica para tal ideia é perfeitamente arbitrária. Se não fosse o caso, a noção de valor perderia algo de seu caráter, pois conteria um elemento imposto de fora. Mas de fato, os valores continuam a ser inteiramente relativos, e eis porque o vínculo entre a ideia e o som é radicalmente arbitrário.

Nota-se, assim, que o arbitrário do signo se localiza não apenas no interior da célula que constitui o signo, como também "no nivel das fronteiras traçadas pelas segmentações que constituem o sistema da língua" (ARRIVÉ, 2008, p. 41, tradução nossa).

Os aspectos destacados por Arrivé (2008) mostram que, no CLG, está visivel a recusa saussuriana à abordagem da língua como representação, notadamente no que diz respeito à questão da arbitrariedade do signo.

No nosso entender, porém, quando confrontamos essa recusa revelada no Curso com a sua presença nos manuscritos saussurianos, especificamente aqueles que foram sistematizados por Bouquet e Engler, podemos vislumbrar, com mais nitidez, seu alcance e efeitos. 
O pai da linguística denuncia a "maneira tradicional de considerar a linguagem quando se quer tratá-la filosoficamente [...]", e continua: "Muito mais grave é o segundo erro em que caem, geralmente, os filósofos que é o de representar" (SAUSSURE, 2004, p. 198).

Considera, então, um engano conceber "Antes o objeto, depois o signo; portanto (o que negaremos sempre) base exterior dada ao signo e representação da linguagem por esta relação" (SAUSSURE, 2004, p. 198). Assim, para o mestre genebrino, essa questão dos objetos ou ideias representados por nomes implicam a dualidade externo versus interno, ou melhor, implicam "reduzir a lingua a algo externo" (SAUSSURE, 2004, p. 198), dualidade esta cuja discussão se reveste de importância.

Convém realçar, portanto, que a recusa saussuriana ao caráter representacional da língua não pode ser tratada como um fato natural, não devendo, portanto, ser simplificada, na medida em que esse fato levanta questões e gera consequências no que toca ao edifício linguístico erguido pelo genebrino. Pretendemos, então, abordar a questão do dualismo interno-externo e duas consequências que dela advêm: a noção de identidade - que implica a noção de corpo do falante - e o dualismo acontecimento versus estado de língua, na tentativa de indicar questões e paradoxos esboçados por essas consequências.

\section{O DUALISMO INTERNO VERSUS EXTERNO}

Sobre o principio de dualismo, Saussure (2004, p. 24) afirma:

O dualismo profundo que divide a linguagem não reside naquele do som e da ideia, do fenômeno vocal e do fenômeno mental, mas do fenômeno vocal COMO TAL e do fenômeno vocal COMO SIGNO - do fato físico (objetivo) e do fato físico-mental (subjetivo), de maneira alguma do fato "físico" do som por oposição ao fato "mental" da significação.

A esse respeito, argumenta o linguista que, se considerarmos o termo francês mer do ponto de vista de uma sucessão sonora $(m+e+r)$, não estamos tratando de uma entidade linguística, na medida em que "não há nenhuma entidade linguística, que possa ser dada, que seja dada imediatamente pelo sentido; nenhuma que exista fora da ideia que lhe pode ser vinculada" (SAUSSURE, 2004, p. 23). Temos, portanto, um vínculo entre objetos heterogêneos ("signos"-ideias), posto que não existe nada em comum entre os "signos"1 e o que eles significam. Desse modo, a sucessão sonora, no exemplo dado antes, seria uma figura vocal que não consistiria em uma entidade linguística. Nessa perspectiva:

Há um primeiro domínio, interior, psíquico, onde existe o signo e a significação, um indissoluvelmente ligado ao outro; há um segundo, exterior, onde existe apenas o signo mas, nesse momento, o 'signo' se reduz a uma sucessão de ondas sonoras que merece de nós apenas o nome de figura vocal (SAUSSURE, 2004, p. 24).

Ao comentar essa proposta de Saussure, Testenoire (2018b) diz que a oposição, para o genebrino, situa-se entre o que ele denomina "figura vocal" e a for-

1 Em alguns momentos da elaboração saussuriana, o autor usa o termo signo na acepção de significante. Achamos por bem, nesses casos, colocar "signo" (entre aspas), a fim de não confundir com signo concebido como associação entre significante e significado. 
ma-sentido. Lembra, então, que a figura vocal é uma sequência de sons que não está ligada a nenhuma significaçāo; é um objeto puramente fisiológico e acústico, sendo, assim, objeto da fonética acústica e da fonética histórica.

Porém, conforme Saussure propõe na Essência dupla da linguagem, no momento em que uma sequência de sons se liga a uma significação, isso se torna uma forma-sentido. A "forma-sentido" tem como propriedades: ser uma associação do som com o sentido; ser uma entidade física e psicológica. É, então, essa "forma-sentido" que será o objeto do linguista: o som na medida em que ele faz sentido, que ele é portador de significação. Essa designação forma-sentido será substituída por signo, 20 anos depois, nos cursos de linguística geral.

Para ilustrar a transformação de figura vocal em "signo" linguístico, Saussure (2004, p. 38) formula o seguinte exemplo:

Uma figura vocal se torna uma forma a partir do momento em que é introduzida no jogo de signos que se chama língua, da mesma maneira em que um pedaço de pano, jogado no fundo do navio, se torna um sinal no instante em que é içado $1^{\circ}$ entre outros signos içados no mesmo momento e que contribuem para uma significação [...].

Desse modo, antes de ser içado entre outros "signos" - com os quais passa a manter uma relação diferencial -, o pedaço de pano não corresponderia a uma forma, mas a uma figura que manteria com outras figuras uma relação de identidade (cor, formato, textura etc.), podendo representar objetos ou fatos do mundo.

Sobre essa relação representativa: objeto - nome $\left({ }^{*}-\mathrm{a}\right)^{2}$, afirma o autor que "a verdadeira relação é $\mathrm{a}-\mathrm{b}-\mathrm{c}$, fora de qualquer conhecimento de uma relação efetiva como *- a, baseada em um objeto" (SAUSSURE, 2004, p. 198).

Assim, a figura vocal se situa em uma relação de exterioridade no tocante ao signo, ou melhor, no tocante à língua. Por sua vez, o "signo" linguístico somente existe por meio de uma relação de diferença com os outros "signos" - a "verdadeira relação" -, o mesmo acontecendo com a ideia que lhe é indissociável, o que consiste na essência do conceito de valor.

Abrimos, aqui, um parêntese para destacar que o signo como associação (indissolúvel) entre significante e significado seria uma entidade positiva, o que coloca uma questão no que diz respeito à concepção de valor, ou seja, às relações diferenciais/opositivas/negativas necessárias para que existam tanto os significantes como os significados. Alguns autores tentam resolver a questão afirmando que o signo saussuriano é posterior e não anterior a essas relações diferenciais, na medida em que o vínculo entre sons e conceitos é "o resultado de uma operação constitutiva cujo sujeito é o próprio sistema no qual os signos estão inseridos" (LAHUD, 1977, p. 34), o que se fundamenta no seguinte excerto do CLG:

Um sistema linguístico é uma série de diferenças de sons combinadas com uma série de diferenças de ideias; mas essa confrontação de um certo número de signos acústicos com outros tantos recortes feitos na massa de pensamento engendra um sistema de valores; e é tal sistema que constitui o vínculo efetivo entre os elementos fônicos e psíquicos no interior de cada signo (SAUSSURE, 1989 [1916], p. 139-140). 
No entanto, vale lembrar também que está presente no Curso a afirmação de que: "Conquanto o significado e o significante sejam considerados, cada qual à parte, puramente diferenciais e negativos, sua combinação é um fato positivo" (SAUSSURE, 1989 [1916], p. 140). Não nos deteremos nesse ponto polêmico, o que nos desviaria do foco de nosso trabalho, mas convém destacar que, em virtude de sua complexidade, a questão permanece, possuindo desdobramentos, como mostra a discussão realizada por Lier-De Vitto (2017) ${ }^{3}$. Segundo essa autora, o signo saussuriano permanece preso a uma visão reducionista/metafisica, isto é, a uma concepção de "relação positiva dentre imagem acústica e conceito e independente do sistema (do objeto da Linguística)" (LIER-DE VITTO, 2017, p. 57).

Fechando o parêntese, pelo que foi posto antes, a figura vocal existe fora da relação diferencial que dá lugar à forma significante, havendo, portanto, suspensão de sentido. Nessa perspectiva, a figura vocal pertence ao domínio fisiológico-acústico (não linguístico), existindo, então, "para o físico, para o físiologista, não para o linguista e nem para o sujeito falante" (SAUSSURE, 2004, p. 67). Por sua vez, é de sua relação de identidade (semelhanças e diferenças) sonora com outras figuras vocais que decorre sua existência. A esse respeito, apresenta o seguinte exemplo:

O fato, por exemplo, de aka ser pronunciado por uma pessoa, num certo lugar e num certo momento, ou o fato de mil pessoas, em mil lugares e em mil momentos, emitirem a sucessão de sons aka, é, absolutamente, o único fato dado: mas não é menos verdade que só o fato ABSTRATO, a identidade acústica desses aka forma sozinha a entidade acústica aka: e não há um objeto primeiro a ser procurado, mais tangivel do que esse primeiro objeto abstrato (SAUSSURE, 2004, p. 33).

Como podemos notar, em relação à concepção saussuriana de figura vocal versus forma, destaca-se a questão da identidade, exigindo, portanto, uma abordagem dessa questão.

\section{Figura VOCAL VERSUS FORMA: A gUESTÃo DA IDENTIDADE}

Segundo Saussure (1989 [1916], p. 126), “o mecanismo linguístico gira todo ele sobre identidades e diferenças, não sendo estas mais que a contraparte daquelas", destacando-se, no CLG, exemplos que apontam para diferentes tipos de identidade:

Assim falamos de identidade a propósito de dois expressos "Genebra-Paris, 8hs 45 da noite", que partem com vinte e quatro horas de intervalo. Aos nossos olhos, é o mesmo expresso, e no entanto, provavelmente, locomotiva, vagões, pessoal, tudo é diferente. [...]

Oponhamos aos casos precedentes, o caso - assaz diferente - de um traje que me tivesse sido roubado e que eu reencontro na loja de um adeleiro. Trata-se de uma entidade material que reside unicamente na substância inerte, o pano, o forro, os aviamentos etc. Um outro traje, por parecido que seja ao primeiro, não será o meu” (SAUSSURE, 1989 [1916], p. 26).

3 Remetemos a essa autora para uma discussão sobre alguns pontos de impasse no pensamento saussuriano. 
Em seguida, coloca: "Mas a identidade linguística não é a do traje, é a do expresso [...]" (SAUSSURE, 1989 [1916], p. 126). Assim, um significante possui identidade em virtude de suas diferenças, ou melhor, sua identidade decorre das diferenças em relação aos outros significantes, o que consiste na identidade do valor.

A esse respeito, recorremos, mais uma vez, a Milner (2003), que acrescenta um aspecto a essa identidade do valor. Em relação ao fonema, esse linguista afirma que, a partir das oposições distintivas, o fonólogo abstrai os traços: sonoro, oclusivo, nasal. Convoca, então, Russell ${ }^{4}$, para quem "as definições por abstração devem ser generalizadas a toda relação que apresente as características da relação de equivalência: simetria, transitividade e reflexividade" (MILNER, 2003, p. 168, tradução nossa). Como consequência, infere que a abstração dos traços distintivos dos fonemas, pelo fonólogo, supõe as características da relação de equivalência. Assim: se /d/ se opõe a /b/ e /b/ se opõe a /m/, então /d/ se opõe a /m/ (transitividade); se /d/ se opõe a /b/, então /b/ se opõe a /d/ (simetria). "Fica pendente a reflexividade: para autorizar o uso do procedimento de abstração, deve admitir-se que, no dispositivo estrutural, todo elemento está em relação de oposição distintiva a si mesmo" (MILNER, 2003, p. 169, tradução nossa). Ao final da discussão, afirma que o estruturalismo não tematizou a consequência, ou seja, a oposição de um elemento a si mesmo, a qual foi tematizada, explicitamente, pelo hiperestruturalismo ${ }^{5}$.

Sobre a identidade da figura vocal, diríamos que, em sua apreensão, o corpo do falante vem à tona, mostrando-se por meio de suas atividades sensório-perceptuais. É necessário, portanto, na percepção do terno na loja do adeleiro, que o sujeito discrimine identidades (semelhanças e diferenças) substanciais (quanto à cor, costura, formato, tamanho, forro etc.) em um confronto com traços mnésicos de seu terno, para não confundi-lo com outro parecido.

Poderíamos dizer, então, que, na identidade do valor, as características substanciais da figura vocal devem ser apagadas ou encobertas, enquanto, na identidade substancial (da figura vocal) essas características devem ganhar visibilidade, o que significaria supor que, no primeiro caso, o corpo em suas atividades sensório-perceptuais fica encoberto, enquanto, no segundo caso, o corpo se mostra por meio dessas atividades. Já que tocamos na questão do corpo do falante ${ }^{6}$, convém abordar, embora rapidamente, essa noção na proposta saussuriana.

Nos Manuscritos de Harvard, ao tratar o fonema, Saussure afirma: "O ouvido só pode naturalmente decidir semelhanças, identidades e diferenças das percepções, mas suas causas que estão na dependência mútua ou podem (sic) ser supostas ser ali [...] [ilegível]" (cf. PARRET, 1993, p. 202, tradução nossa). Parret (2011) se refere a essa atividade decisória - sobre identidade, semelhanças e diferenças fônicas - como julgamento do ouvido denominando o corpo, na concepção saussuriana, corpo-feito-voz, em vez de corpo-ouvido, como fazem alguns autores. Para aquele autor, na concepção do linguista genebrino, "o corpo está na voz, entre a boca e o ouvido, é essencialmente a voz que impressiona, solicita o ouvido [...]" (PARRET, 2011, tradução nossa).

\footnotetext{
Fazendo apelo a Russel (1919 apud MILNER, 2003, p. 168), o autor explica essa proposta do filósofo em nota de rodapé. Como hiperestruralismo, Milner (2003) se refere à psicanálise lacaniana, destacando a introdução da noção de sujeito na estrutura. Remetemos a Parret (2014), a Carvalho (2019) e a Carvalho e Melo (2018), para uma discussão mais detalhada da noção de corpo do falante em Saussure.
} 
Ao que tudo indica, é importante destacar da noção saussuriana de corpo, na leitura feita por Parret, a questão de seu apagamento. Se de um lado, esse autor afirma: "A expulsão do corpo em um Para-fora impensável, irrecuperável é a condição sine qua non do triunfo do Método, da ciência a advir [...]" (PARRET, 2011, tradução nossa), de outro lado, ele concebe essa expulsão como recalque 7 do corpo: "Se há tantos 'brancos"8 na teoria das cadeias sonoras, é que a negação da voz repousa sobre o recalque do corpo-feito-voz" (PARRET, 2013, p. 14-15, tradução nossa). Nesse último caso, adverte: "Não tenho a menor intenção de fazer emergir o inconsciente saussuriano, e apenas destaco, sem dramatização, algumas sequências a propósito do corpo-feito-voz, fontes do estrito Método" (PARRET, 2013, p. 15, tradução nossa) ${ }^{9}$. Sobre os brancos referidos, coloca o autor:

E Claudine Normand sugere uma hipótese que retomarei inteiramente em minha leitura desconstrucionista de Saussure: é que os 'brancos' mostram que não é fácil, nem mesmo possivel, expulsar da reflexão teórica o som da voz, o gesto da mão, a presença insistente do corpo (PARRET, 2013, p. 2, tradução nossa).

Ao abordar a questão da identidade na proposta saussuriana, Testenoire (2018a) destaca os três tipos presentes no CLG: entre duas figuras vocais (identidade fônica); entre duas formas-sentidos, isto é, entre dois signos em um mesmo estado de lingua (identidade sincrônica) e entre dois signos em épocas diferentes, por exemplo, a palavra francesa chaud e o latim calidum (identidade diacrônica).

Em relação à identidade fônica, destaca que ela é construída por meio de uma atividade reflexiva (epilinguística ou metalinguística), diferentemente da identidade sincrônica "imediatamente perceptivel pelo sujeito falante" (TESTENOIRE, 2018a, p. 81). Para ilustrar essa diferença, recorre à homofonia convocando o exemplo formulado por Saussure: "Um homem que vive em Cher pode passar a vida inteira sem se dar conta de que o nome de sua província não difere, em seus sons, da palavra que ele pronuncia em cher ami” (SAUSSURE, 2004, p. 47).

Desse modo, Testenoire (2018a) toca na questão da homofonia cuja complexidade é por ele reconhecida ao indicar o seguinte paradoxo: "Embora ele [Saussure] tenha colocado, em A essência dupla, a não existência linguística da figura vocal para o sujeito falante, ele determina aqui sua existência para o sujeito desenvolvendo uma abordagem reflexiva da língua" (TESTENOIRE, 2018a, p. 80, tradução nossa).

Assim, a expulsão da figura vocal para fora da língua contém a negação dessa expulsão, ou melhor, ao mesmo tempo que a figura vocal é expulsa do sistema linguístico saussuriano, ela é introduzida para o interior desse sistema, por meio da abordagem da homofonia, ou seja, por meio do reconhecimento da homofonia pelo falante.

\footnotetext{
Como se pode notar, Parret (2013) utiliza o termo recalque no sentido psicanalítico, isto é, como o "Processo de afastamento das pulsões às quais é rejeitado o acesso à consciência" (CHEMAMA, 1995, p. 185), o que implica, como sua outra face, o retorno do recalcado.

8 É Claudine Normand (2006 apud PARRET, 2013) quem utiliza esse termo - blanc (branco) -, levantando hipóteses sobre a existência de brancos na reflexão saussuriana.

9 Sobre essa questão do apagamento do corpo na concepção saussuriana de língua, ver Carvalho (2019)
} 
Outro caso ilustrativo desse paradoxo pode ser indicado por um dentre os grupos associativos propostos no CLG, isto é, grupos cuja formação atende à lei associativa de funcionamento da lingua. Trata-se do grupo cujos termos se relacionam pelo critério apenas do significante, ou melhor, da

[...] simples comunidade das imagens acústicas (por exemplo enseignement $e$ justement, ou ensinamento e lento). Por conseguinte, existe tanto comunidade dupla do sentido e da forma, como comunidade de forma ou de sentido somente (SAUSSURE, 1989 [1916], p. 145-146).

Podemos dizer que se trata de um grupo constituído por meio do critério fônico, uma vez que, nas palavras que o constituem, o sentido - e a forma à qual o sentido se associa - é suspenso, vindo à tona a semelhança fônica entre partes dos termos que compõem esse grupo. Dizendo de outro modo, ao serem reunidos nesse grupo, os termos perdem seu caráter de significante, adquirindo o estatuto de figura sonora. Convém indicar a polêmica existente em torno do grupo associativo destacado. No CLG, em nota de rodapé, ele é concebido como sendo de um nível inferior: "[...] sua existência, porém, é provada por uma categoria inferior de jogos de palavras que se funda em confusões absurdas que podem resultar do homônimo puro e simples [...]" (SAUSSURE, 1989 [1916], p. 145-146).

No entanto, vários autores, como Testenoire (2018a) e De Mauro em Saussure (1985 [1916]), sustentam que tanto esse grupo teria sido concebido por Saussure embora os exemplos provavelmente não fossem de sua autoria - como a nota que o desqualifica teria sido acrescentada pelos editores. A respeito desse grupo, convocamos mais uma vez Testenoire (2018a, p. 72, tradução nossa), que afirma:

Contrariamente a seus dois alunos, ele [Saussure] não desconhecia a importância desses fenômenos no funcionamento linguístico e na atividade discursiva dos sujeitos falantes. [...] sem reservar a essa última categoria um estatuto inferior.

Indagamos, então, se a polêmica referida não seria uma outra realização do paradoxo citado antes, ou seja, se de um lado, a figura vocal é expulsa - ou é recalcada - da língua como sistema, de outro lado, ela retorna no interior desse sistema, constituindo critério de formação de um grupo que atende a uma lei linguística/sistêmica.

Do que foi posto sobre a homofonia, podemos inferir que, nessa identidade fônica, trata-se da transformação de significante em figura vocal.

É importante indicar que, de algum modo, questões colocadas pela identidade estão presentes na abordagem saussuriana do dualismo acontecimento versus estado de lingua que trataremos a seguir.

\section{ACONTECIMENTO VERSUS ESTADO DE LÍNGUA}

Para Saussure (2004, p. 191), "Cada vez que se produz, na lingua, um acontecimento pequeno ou grande, a consequência é por evidência que o estado recíproco dos termos, considerado depois do acontecimento, não é mais o mesmo de antes".

Para fundamentar essa afirmação, ele dá exemplos de mudanças fonético-morfológicas e sua relação com o estado de língua delas decorrente. É o caso da queda do $t$ final no termo grego egnõt, acontecimento que não diz respeito ao 
termo egnõn; no entanto, se considerarmos o estado da língua, constatamos que a relação recíproca egnõn: egnõt é substituída pela relação egnõn: egnõ. Assim, segundo o autor, embora o acontecimento seja a causa do estado e o explique, uma posição reciproca dos termos - isto é, um equilíbrio entre eles - jamais é dada "pelo catálogo de acontecimentos, essa posição é essencialmente diferente dos acontecimentos" (SAUSSURE, 2004, p. 193). Desse modo, as mudanças nas relações entre os termos de um estado de língua não se assemelham, de modo algum, aos acontecimentos que lhe deram origem.

Sobre o dualismo - acontecimento versus estado -, na perspectiva saussuriana, Lemos (2006) destaca que mesmo mudanças profundas não provocam rupturas na comunidade linguística, o que o genebrino havia ilustrado, de forma exemplar, por meio da atividade de reconstituição de um formigueiro, colocando: "Isso lembra o formigueiro em que se enfia uma vareta e que, no mesmo instante, tem seus danos reparados, estou querendo dizer que a tendência ao sistema ou à ordem não se abate jamais [...]" (SAUSSURE, 2004, p. 227).

Por sua vez, ancorada na proposta saussuriana, aquela autora discute exemplos de acontecimentos fonéticos e afirma: "Que o falante se dê conta ou não desse acontecimento fonético que está na origem dessa mudança sistêmica é absolutamente irrelevante para sua atividade enquanto tal" (LEMOS, 2006, p. 25).

Essa ausência de reconhecimento (consciente) leva a autora citada a colocar em realce o movimento mútuo entre fato de fala (fait de parole) e fato de lingua (fait de langue), na doutrina saussuriana. Propõe, então, em relação ao fato de fala, que o falante, em seus usos da lingua, oblitera ${ }^{10}$ os acontecimentos que deram origem à mudança; por sua vez, desde que o fato de fala seja assimilado ao sistema da lingua (fato de lingua), são obliteradas as características acidentais/contingentes desse fait de parole, bem como os acontecimentos que lhe deram origem como, por exemplo, fatos históricos, socioculturais, psicológicos.

Convocamos, neste momento, uma ilustração apresentada por Saussure, no âmbito da mitologia, que mostra tanto o dualismo acontecimento versus estado de língua como também, e sobretudo, a transformação da figura vocal em significante, dois fenômenos que se encontram intimamente ligados. Essa transformação já foi aqui ilustrada - com o exemplo do pedaço de pano lançado no fundo do navio -, mas a ilustração saussuriana que diz respeito a seres mitológicos ${ }^{11}$ oferece uma maior riqueza de detalhes: trata-se da transformação do nome Agni (um deus védico) em significante.

Transcrevemos, a seguir, um longo trecho dos Escritos que consideramos necessário à abordagem de alguns aspectos implicados na mencionada transformação:

Enquanto subsiste uma conformidade de nome (simplesmente de nome) entre um objeto óbvio e os [], há uma primeira categoria de seres mitológicos dignos de serem opostos fundamentalmente aos outros, como classificação primeira da ideia mitológica. Então, o nome é o princípio decisivo, o único, não da invenção dos seres mitológicos - porque quem investigaria isso em seus fundamentos? mas do instante em que os seres se tornam puramente mitológicos e rompem sua última ligação com a terra para povoar o Olimpo depois de muito [ ] (SAUSSURE, 2004, p. 189).

\footnotetext{
10 Posteriormente, Lemos (2014) substitui o termo obliterar por recalcar no sentido psicanalítico.

11 Os dois exemplos estão na publicação Escritos de linguística geral (SAUSSURE, 2004), mas pertencem a dois conjuntos de documentos: o primeiro pertence ao Acervo BPU descoberto em 1996, enquanto o segundo, à Edição Engler 1968-1974.
} 
Na ilustração recortada, de acordo com a caracterização saussuriana de figura vocal versus forma (presente no Acervo BPU 1996), o nome Agni, em um tempo anterior, consistiria numa figura vocal. Nessa perspectiva, teríamos, então, uma sequência de sons que mantém, com outras sequências, não uma relação diferencial, mas sim uma relação substancial: possui uma identidade fônica com agni (fogo).

Enquanto a palavra agni designa ao mesmo tempo, daí a confusão, o fogo de todos os dias e o deus Agni, enquanto Djeus é, ao mesmo tempo, o nome de [ ], é impossível faça-se o que for, que Agni ou Djeus sejam da mesma ordem de Varuna ou [...], cujos nomes têm a particularidade, no mesmo momento, de nada designar sobre a terra (SAUSSURE, 2004, p. 189).

Assim, tanto Agni como agni possuiriam, inicialmente, uma mesma referência, ou melhor, designariam o mesmo objeto terreno: o fogo. Teria ocorrido, entretanto, um acidente de natureza linguística (um acontecimento): o surgimento de vários nomes que se associam a agni para também designar o objeto fogo. Esse acontecimento/acidente/contingência linguística teria provocado a transformação do nome do Deus em significante, isto é, teria transformado Agni em um nome que se relaciona diferencialmente com outros nomes do Olimpo, rompendo qualquer ligação com objetos terrenos. A esse respeito, coloca Saussure (2004, p. 189): "Se há um instante determinado em que Agni deixa de participar [ ], esse instante consiste apenas no acidente que trará a ruptura de nome com o objeto sensível, como o fogo". "E, nesse momento, o deus Agni será INEVITAVELMENTE promovido à condição de divindade inescrutável como Varuna" (SAUSSURE, 2004, p. 190), ou melhor, passa a pertencer a uma mais vasta categoria de seres do Panteão dos povos antigos que "provém não da impressão produzida por um objeto real, tal como agni, mas do jogo infinito dos epítetos que rolam sob cada nome, permitindo, a cada instante, criar tantos substitutos (de '[ ]') quantos se queira [ ]" (SAUSSURE, 2004, p. 190).

$\mathrm{O}$ autor se pergunta a que se relaciona uma mudança tão decisiva em mitologia e, em sua resposta, indica que tal mudança se relaciona a fatos que extrapolam o âmbito linguístico, mas que "não têm importância visível no curso dos acontecimentos linguísticos de cada dia" (SAUSSURE, 2004, p. 190); seriam, por exemplo, fatos socioculturais, conforme colocado antes.

Podemos, enfim, realçar que a ilustração a que o linguista genebrino recorre, no âmbito mitológico, lança luz sobre o movimento de transformação da figura vocal em significante, considerando a dimensão sistêmica da língua.

\section{CONSIDERAÇÕES FINAIS}

Retomaremos alguns pontos colocados, neste artigo, por meio de dois exemplos: um que ilustra a homofonia (Cher=cher) e o outro que ilustra a passagem de um nome (Agni, o nome de um deus védico) da condição de figura vocal para a condição de significante.

Lembremos que um confronto com essas ilustrações levou-nos a conceber dois movimentos inversos: no primeiro caso, trata-se de um movimento de transformação de significante em figura vocal, enquanto no segundo, a figura vocal transforma-se em significante. Um olhar mais atento nos leva a inferir que, 
nesses movimentos, trata-se de dois tipos de figura vocal, ou melhor, a figura vocal adquire estatutos diferentes em cada um dos casos. Assim, no segundo exemplo, o nome/figura vocal Agni se liga ao referente fogo, assim como o nome agni com o qual mantém uma identidade substancial/fônica. Sua transformação em significante implicaria, então, tanto um apagamento da referência a qualquer objeto terreno, como também um apagamento - ou melhor, um recalque - de sua relação substancial de identidade fônica com outras figuras vocais, adquirindo sentido em sua relação diferencial com outros nomes. No caso da identidade fônica na homofonia do primeiro exemplo, o surgimento da figura vocal (Cher=cher) suspende os sentidos associados aos diferentes usos do significante cher (a cidade Cher e cher ami) e, ao mesmo tempo, essa suspensão não pressupõe qualquer ligação com um referente.

Indagamos, então: não se trataria de um movimento em que, de um lado, a figura vocal é apagada para dar lugar ao significante (Agni) e, portanto, ao sentido e, de outro lado, o significante (cher) perde sua condição de significante para dar lugar à figura vocal extrassenso ${ }^{12}$ ?

Nessa perspectiva, propomos que o fato de ter Saussure excluído a figura vocal como entidade linguística, a fim de elaborar a língua como sistema de valores que só conhece suas diferenças, não estaria indicando apenas um movimento histórico no campo de estudos da linguagem, isto é, uma mudança da concepção de língua como representação para a concepção de língua como sistema; estaria indicando também, em relação ao falante (ou linguista), um contínuo movimento: da figura vocal ao significante e, inversamente, do significante à figura vocal, o que corresponde a propor esse contínuo movimento no interior da própria língua em sua concepção sistêmica.

Indagamos, ainda, para finalizar: não estaríamos apontando, na proposta saussuriana, para um movimento de mão dupla em relação ao corpo do falante (ou linguista)?

Nessa perspectiva, ora o corpo - que aparece na escuta da figura vocal - é recalcado, dando lugar ao aparecimento do significante, ora esse corpo que fora recalcado retorna no significante, dando lugar à escuta da figura vocal pelo falante (ou linguista).

Relembrando o que antecipamos na Introdução, este artigo consistiu em uma tentativa de abordar algumas questões e consequências advindas da recusa saussuriana à língua como representação, com o objetivo de quebrar a naturalidade com que, muitas vezes, essa recusa é abordada. Uma das quebras da naturalidade seria mostrar que, embora a recusa da língua como representação implicasse expulsar a figura vocal da língua, essa figura vocal não poderia ser expulsa do falante, na medida em que faria parte de um movimento de mão dupla: da figura vocal na homofonia para o significante e deste para aquela. Reconhecemos, porém, que nos deparamos com questões que, pela sua complexidade, necessitam ainda percorrer um longo caminho de investigação em que sejam considerados hesitações, paradoxos e interrogações que marcam a elaboração do edifício linguístico saussuriano.

12 Extrassenso, na acepção de fora de sentido, é um termo usado por Le Gaufey (2018), consistindo numa tradução, para o português brasileiro, da expressão francesa hors sens. 


\title{
Notes on the SAUSSURIAN REFUSAL to THE NOtion OF LANGUAGE AS REPRESENTATION
}

\begin{abstract}
This article is an attempt to discuss the radical separation between the Saussurian sign and the traditional notion of linguistic sign as representation. We seek to address the issue of internal versus external dualism regarding language and two consequences of this issue: the notion of identity - which implies the speaker's body - and the dualism event versus state of language. We then highlight issues and paradoxes in an effort to break the naturalness Saussure's refusal to the representational conception of language has been dealt with.
\end{abstract}

Keywords: Saussure. Language. Sign. Representation. Dualism.

\section{REFERÊNCIAS}

ARRIVÉ, M. Qu'en est-il du signe chez Ferdinand de Saussure. Journal Français de Psychiatrie, n. 29, p. 39-41, 2008.

CARVALHO, G. M. M. O corpo na elaboração saussuriana do conceito de língua: um ponto paradoxal. Revista D.E.L.T.A, v. 35, n. 2, p. 1-15, 2019.

CARVAlHO, G. M. M.; MELO, M. F. V. A noção de corpo em Saussure e em Freud: um encontro paradoxal. Revista da ANPOLL, n. 45, p. 218-232, 2018.

CHEMAMA, R. Dicionário de psicanálise. Rio de Janeiro: Larousse/Artes Médicas, 1995.

LAHUD, M. Alguns mistérios da linguística. In: GALVÃO, W. N.; PRADO JR., B. (coord.). Almanaque: Cadernos de Literatura e Ensaio, São Paulo, n. 5, p. 28-37, 1977.

LE GAUFEY, G. A incompletude do simbólico: de René Descartes a Jacques Lacan. Campinas: Editora Unicamp, 2018.

LEMOS, C. T. G. Uma crítica (radical) à noção de desenvolvimento na Aquisição da Linguagem. In: LIER-DE VITTO, M. F.; ARANTES, L. (org.). Aquisição, patologia e clínica de linguagem. São Paulo: Educ/Fapesp, 2006. p. 21-32.

LEMOS, C. T. G. A criança e o linguista: modos de habitar a língua? Estudos Linguísticos, São Paulo, v. 43, n. 2, p. 954-964, 2014.

LIER-DE VITTO, M. F. O objeto da linguística: um convite à releitura. Revista Cult, Dossiê Saussure, 100 anos depois, n. 216, p. 54-57, 2017.

MILNER, J. C. El periplo estructural: figuras y paradigmas. Buenos Aires: Amorrortu, 2003.

PARRET, H. Les manuscrits Saussureans de Harvard. Cahiers de Ferdinand de Saussure, n. 47, p. 179-234, 1993.

PARRET, H. Le son et l'oreille: six essais sur les manuscrits saussuriens de Harvard. Limoges: Lambert-Lucas, 2014.

PARRET, H. Le fondement impensable de la théorie linguistique saussurienne. Actes Sémiotiques [on-line], n. 114, 2011. Disponivel em: https://www.unilim. fr/actes-semiotiques / 1865. Acesso em: 27 abr. 2019. 
PARRET, H. L'intimité fuyante de Saussure: "La théorie de la chaîne sonore est une étude des plus [ ]" [Écrits, 241]. Congrès International 100 ans avec Saussure, Université de Sao Paulo, 16-20 de setembro de 2013. Disponivel em: http:// www.hermanparret.be/media/recent-articles/258.pdf. Acesso em: 27 abr. 2019. SAUSSURE, F. de. Cours de Linguistique Générale. Edição crítica preparada por Tullio De Mauro. Paris: Payot, 1985 [1916].

SAUSSURE, F. de. Curso de Linguística Geral. São Paulo: Cultrix, 1989 [1916]. SAUSSURE, F. de. Escritos de linguística geral. Organização e edição S. Bouquet e R. Engler. São Paulo: Cultrix, 2004.

TESTENOIRE, P. Y. Jeux de mots, jeux phoniques et anagrammes dans la réflexion linguistique de Saussure. In: BETTINA, F.; MICHELLE, L. (ed.). Jeux de mots et créativité: langue(s), discours et littérature. Berlin, Boston: De Gruyter, 2018a. p. 69-96.

TESTENOIRE, P. Y. La linguistique générale de Saussure: signe, langue, valeur. In: Actualités de Saussure. Curso proferido na Universidade Católica de Pernambuco, 2018b. 